\title{
Notas sobre la ebanistería madrileña en el siglo XVIII
}

\author{
MARía PAZ Aguiló AlONSO \\ Dpto. de Historia del Arte
}

CSIC. Madrid

\section{RESUMEN}

Ante la idea generalizada de la influencia francesa en el mobiliario español con el advenimiento de los Borbones, se intenta apuntar la importancia creciente del mobiliario inglés en la primera mitad del siglo xviII, al mismo tiempo que dar a conocer el mecanismo de las diversas actuaciones corporativas, desde la reunión en un solo gremio de ebanistas y ensambladores de nogal, su actividad para ejercer con mayor fortaleza su presencia en los foros ciudadanos, el sistema de exámenes con sus piezas determinadas de antemano hasta la importancia de los ebanistas en las labores de tasación, tanto en cartas de dote como en inventarios post mortem. Esta serie de documentos hallados en el Archivo Histórico de Protocolos de Madrid, relativos a las décadas de $1740-1760$, sumándose a los ya publicados, irán completando el conocimiento sobre los ebanistas y ensambladores madrileños del siglo XVIII.

\section{SUMMARY}

By pointing out the increasing importance of English furniture in Madrid in the first half of the $18^{\text {th }}$ century, the author questions the widespread belief that Spanish furniture was under French influence at the time because of the advent of the Bourbons. In addition, the author calls attention to the most salient aspects of the union activity of cabinetmakers and joiners, such as membership of these artisans in a joint labor organization, their strategies to promote their craft as well as the union, the methods of examination used (with pieces selected beforehand) and the important role played by cabinetmakers in value assessments of property, both for deeds of dowry and for postmortem inventories. The author's sources are documents found in the Archivo de Protocolos de Madrid which date to the years between 1740 through 1760 . These documents significantly add new information to the evidence already known about the activities of Madrid's woodwork craftsmen in the $18^{\text {th }}$ century.

Palabras clave: Ebanistas. Historia del mueble. Madrid. Gremios. Siglo XviII. Cartas de examen.

Key words: Furniture. Union of cabinetmakers and joiners. Madrid. Archival documents. Eighteenth century.

RDTP, LVI, 2 (2001): 245-276 
Extendida la idea de la influencia francesa en el mobiliario europeo con el advenimiento de los Borbones, es nuestra intención con estas breves notas apuntar la importancia creciente del mobiliario inglés en la primera mitad del siglo xviI, al mismo tiempo que dar a conocer el mecanismo de las diversas actuaciones gremiales, desde la reunión, que no fusión, de ebanistas y ensambladores de nogal, su actividad para ejercer con mayor fortaleza su presencia en los foros ciudadanos, el sistema de exámenes con sus piezas determinadas de antemano hasta la importancia de los ebanistas en las labores de tasación, tanto en cartas de dote como en inventarios post mortem $^{1}$.

Durante el primer tercio del siglo XVIII, las noticias obtenidas a través de los inventarios nos muestran el tipo de mobiliario que se utilizaba y de su lectura se desprende la persistencia de tipos de muebles propios del siglo XVII, que, pese a las fuertes influencias italianas, habían adquirido el suficiente grado de hispanización para ser considerados como tales. Aparecen en los inventarios guardarropas, tocadores, cofres, escritorios y escaparates. Con una sobresaliente novedad respecto a lo anterior, se citan con bastante asiduidad muebles de charol, es decir lacados (Barrio Moya 1998a: 409). Esta técnica decorativa, puesta de moda en Inglaterra a finales del siglo anterior a partir del tratado de Parker y Stalker, seguida de modo enfervorizado sobre todo por el mundo femenino británico $^{2}$, se ha venido considerando que se introdujo en España a partir de la importación de piezas de un comerciante inglés Giles Grendley, a mediados de la década de los treinta, especialmente una serie de muebles de laca roja realizada para los duques del Infantado en su palacio de Lazcano (Symonds 1935 y 1941: 57) ${ }^{3}$. Es sabido que el comercio inglés penetró en la Península por tres focos bien localizados: Oporto, Cádiz y Bilbao, aunque no se conoce aún documentación puntual sobre este tráfico comercial respecto al mobiliario ${ }^{4}$. Lo cierto es que conocemos ya un abundante número de muebles lacados de factura andaluza, lo que indica que se hicieron allí y, por otro lado, los datos inventariales aportados, en los que aparecen estas piezas en Madrid, suelen referirse a personas de ascendencia $u$ origen vasco.

\footnotetext{
${ }^{1}$ Agradezco a M.. Luisa Tárraga su gentileza al proporcionarme gran parte de los documentos utilizados para este estudio.

2 Treatise of Jappaning, Varnishing. London 1678.

${ }^{3}$ Los procedentes de Infantado han aparecido en los últimos diez años en subastas internacionales, atribuyéndose al comerciante sillero londinense todos los muebles similares que se encuentran en España.

${ }^{4}$ El denominado Trait of Streit aclara datos sobre el comercio de la madera, pero no sobre manufacturas.
} 
Una aportación al conocimiento de la importancia que el mueble inglés tuvo en España en la primera mitad del siglo XVIII, viene dada por el Álbum del marqués de la Victoria en el que aparecen dibujos de muebles, prácticamente todos de gusto inglés, con sus correspondientes denominaciones ${ }^{5}$, con lo que se pueden sentar bases seguras, tanto documentales como gráficas, algo inusual en la historia del mueble (Piera 1998).

Por otro lado, la documentación gremial del siglo xviII, cuyo estudio detenido y comparativo entre diferentes poblaciones resulta básico para establecer un hilo conductor que permita conocer la incidencia de diferentes tipos de muebles en diferentes sociedades, la inclinación de unas regiones por unos $\mathrm{u}$ otros tipos, al modo como se ha hecho respecto a los siglos XVI y XVII (Aguiló 1993), ha sido, en general, publicada de modo muy fragmentario. En general se han editado estudios importantes sobre gremios y su actividad en toda España, pero los dedicados concretamente a los de la madera, casi por completo se centran en el último tercio del siglo xviII, como los de Piera en Barcelona o L. Castán en Madrid.

En Cataluña, excepto en Barcelona todos los artesanos de la madera pertenecían a una sola corporación, incluso con otros oficios como la albañilería o el hierro. El Gremio de Carpinteros de Barcelona agrupaba algunos entre los que se suscitaban numerosos litigios como el que en 1752 mantuvieron los silleros y guarnicioneros contra los carpinteros, o los mantenidos durante los siglos anteriores con los escultores, quienes se separan en 1688 (Molas 1972: 264; Aguiló 1993: 44-68). Pese a todo, pleitean continuamente, hasta el punto que en 1746 la cofradía de escultores prohibirá el ingreso en esta de los hijos de los carpinteros (Piera y Mestres 1999). La documentación publicada sobre carpinteros barceloneses en esa primera mitad del siglo xviII se reduce exclusivamente a extractos mínimos de inventarios post-mortem, excepto un documento en el que el Gremio de Carpinteros argumenta contra los silleros:

...esto es notorio y se ve patente en las arcas, baules, arquillas, escritorios, papeleras, calaxeras, otros artefactos en cuyos para una entera perfeccion y cumplimiento son necesarias differentes piessas de hierro y cobre o latón como sarrajas, quicios vulgo frontisas, aldabas y otras piezas, quales las han puesto y clavado siempre los mismos carpinteros y es preciso que lo hagan ellos mismos assi por acordar y ponerse cada una de ellas en el lugar que corresponde de dichos artefactos, como y porque en otra manera estos sin dichas piezas quedarian imperfectos e informes, co divididas y ceparadas las partes o piezas de madera que juntas forman el artefacto con toda perfeccion y cumplimiento [...]

y si esto procede respecto a las piezas de cobre o latón, parece que por semejantes razones debe proceder lo mismo acerca los artefactos de madera que por su

\footnotetext{
${ }^{5}$ Conservado el original en el Museo Naval de Madrid, fue publicado en 1995.
} 
entera perfeccion y cumplimiento necessitan de forrarse e cobrirse el cuero o de qualquier especie de ropa (Piera 1999: 296) ${ }^{6}$.

La documentación catalana publicada, referente a mediados de siglo, aporta pruebas sobre el comercio y la influencia inglesa. Si hacia 1730 se registran solo muebles del gusto del siglo anterior, a partir de $1740 \mathrm{co}-$ mienzan a aparecer en los inventarios (1751) sillas de Inglaterra y sillas $a$ la inglesa, es decir, importadas o hechas según modelos originales, incluso éstas aparecen de asiento de marroqui, o con asiento y arrimadero de pergami rexat o encordadas de pergami (Piera 1999: 125). En cambio, las sillas de paja, que tanta importancia adquirieron a partir de 1775 en Cataluña, parece ser, por el estudio citado, que fueron copiadas e importadas de Nápoles (Larruga 1788: CXXIV-II, 262; Piera 2000). En cambio, no se han publicado aún documentos sobre exámenes de maestría de fusteros, anteriores a 1784 y 1785 , que nos permitan establecer correlaciones con los que tienen lugar en Madrid entre 1740-1775.

López Castán, en sus estudios referentes al último tercio del siglo en Madrid, refiriéndose a la reestructuración de 1776, concretamente al Informe redactado por Agustín de la Cava, Francisco Antoine y Pedro Davount, publicado en 1780 en las Memorias de la Sociedad Económica "Memorias de Artes y Oficios", bajo el título genérico de "Ordenanzas de los diez gremios de artesanos que en esta corte se dedican a labrar la madera", y de un modo más específico el Gremio de Ebanistas, aporta numerosas noticias sobre actuaciones gremiales, exámenes de ebanistas, etc., incluyendo el contenido extractado de los quince capítulos añadidos en 1748 a las Ordenanzas de 1675, una vez unificados los gremios de ebanistas y entalladores y ensambladores de nogal (López Castán 1998).

Un primer punto sobre el que llamar la atención sería que, durante este siglo, los ebanistas no guarden demarcación urbana, a diferencia de otros oficios obligados a residir en una calle o barrio. Castán, siguiendo a Entrambasaguas y a Agulló, lo había localizado en el siglo XVII al este de la Puerta del Sol (1986: 22) y, por los datos que hemos encontrado en la documentación que aportamos en torno a los años centrales del siglo, un buen número de ellos está asentado en San Jerónimo, pero aparecen citados desde la calle de San Juan hasta la de Fuencarral, Huertas o Magdalena, si bien es cierto que en los documentos - la mayoría cartas de examen-, no se precisa el lugar de residencia del examinado, constatándose solo su origen y edad al acceder al examen. El resto de los oficios integrados en el gremio, carpinteros, torneros y puertaventaneros

\footnotetext{
${ }^{6}$ AH. Ciutat Gremi de Fusters 37-61. Punt 25. (Cfr. Piera 1999: 296).
} 
tuvieron sus tiendas y talleres entre las calles Toledo, Mayor y Atocha, junto a los doradores de mate.

Esta serie de documentos procedentes del Archivo Histórico de Protocolos de Madrid, entre los que se cuentan siete exámenes y catorce inventarios y tasaciones entre 1742-1753, sumándose a los ya publicados, irán completando el conocimiento sobre los ebanistas y ensambladores de mediados del siglo XviII. En una de las papeletas publicadas por A. González Palencia se constata la agrupación el 25 de septiembre de 1753 de 33 maestros:

individuos de ambos gremios de ebanistas y ensambladores de nogal en una de las salas del convento de Santo Tomás, Orden de Predicadores de esta Corte [...] como lo tienen por uso y costumbre... (González Palencia 1953: 481)

dando poder a uno de ellos para nombrar veedores, puesto que a pesar de lo acordado estuvo vacante más tiempo de lo habitual. Los nombres de todos ellos son esencialmente los mismos a los que se refieren nuestros documentos, además del dato de su lugar de reunión en el convento de Santo Tomás, el nombramiento bianual, el día de San Lorenzo, de los dos veedores que velarán por el buen hacer de los agremiados. Así a lo largo de las dos décadas que comentamos, se observa que estas parejas de veedores, uno por los ebanistas y otro por los ensambladores de nogal, suelen aparecer al mismo tiempo también como examinadores: Manuel Rodríguez y Gabriel Muñoz (Docs. 1-4) o Sebastián de Bustos y Manuel Sacristán, los primeros ebanistas y los segundos entalladores y ensambladores de nogal (Docs. 5-7). Un documento similar se redacta veinte años después 1774 (Doc. 11) con diez maestros menos, mientras que en 1776 el número total es de 76 maestros ebanistas, entalladores y ensambladores de nogal, según la Lista de yndividuos del Gremio de Ebanistas de esta Corte realizada en 1775 (López Castán 1998: 208-9) ${ }^{7}$.

La idoneidad de la reunión de ambos oficios, ebanista y ensamblador de nogal, supone un largo proceso de adaptación, de mantenimiento de atribuciones muy similares pero aún diferentes, que se hacen constar de manera explícita en los documentos. El romper las barreras entre ambos es difícil, pero a veces se logra hacer de manera sutil. Un ebanista, Francisco López, en su carta de dote para casarse (1751) con la viuda de otro ebanista (Doc. n. ${ }^{\circ}$ 9), aporta herramientas y madera, dice que de ebanista, pero por las piezas que se enumeran, parece más un ensamblador,

\footnotetext{
7 Esta lista se conserva en el Archivo de la Sociedad Económica Matritense de Amigos del País. Leg. 1, doc. 6.
} 
pues a excepción de un par de papeleras de nogal y concha, el resto de lo que aporta está relaccionado con el oficio de ensamblador y tallista (por ejemplo, catres y lechos para camas), especializado además en la construcción de asientos. Vemos que tiene sillas francesas a medio terminar $^{8}$, sillas corrientes, de costillas, cerda para rehenchir algunas, diferentes tipos de clavazón y solo dos taburetes a la inglesa, además de copetes y elementos tallados y por tallar, utilizables en esas últimas. Solo tiene una pieza de madera fina, sin aplicación directa, y los bufetes, papelera y cama, parecen aportaciones de mobiliario pertenecientes al ajuar, no a su oficio, es decir, no pertenecientes al taller sino a la vivienda.

Lógicamente un ensamblador, como se denominaría en el siglo XVII, mejora su posición si se hace ebanista, y un paso previo para poder llegar a ello es casarse con una viuda de ebanista, lo que, a partir de las dictadas en 1675, está ya contemplado en las Ordenanzas. En las de 1748, fecha en que se añaden los quince nuevos capítulos, el ensamblador pertenecería al segundo grupo de oficiales con los entalladores, dejando solos a los ebanistas, quienes debían pasar otro examen distinto, "para obras taraceadas". Toda la obra que este Francisco López aporta, puede incluirse, sin ningúna desviación del capítulo IX de las nuevas ordenanzas que incluye: sillas, taburetes, sitiales, catres, canapés, pilastras, pedestales, cofres para joyas, papeleras, tocadores, imperiales, marcos, tanto de nogal, como de haya o álamo, mientras el pino quedaba en exclusividad para los carpinteros, hasta la Real Resolución de 1799, por la que se da libertad a los gremios para el uso de todas las maderas, tanto finas como ordinarias.

En las ordenazas de 1748 se continúa con la preceptiva necesidad de seis años para aprendices y cuatro para oficiales, como se desprende de la carta de examen de maestro entallador y ensamblador de Miguel López dada el 28 diciembre 1744:

en cumplimiento de lo acordado y determinado en punto de los que recibiesen a examen en la Junta que por ambos gremios se celebro en el dia cinco de diciembre del año proximo pasado de mil setecientos cuarenta y tres (Doc. n. ${ }^{\circ}$ )

No se ha localizado aún el documento relativo a la redacción en 1743 de esa junta en la que se ven robustecidos ensambladores y entalladores juntos, frente a los carpinteros. Tampoco aparecen reglamentadas las pruebas de maestría, pero de este mismo documento se desprende que una de las piezas de examen debía ser:

\footnotetext{
${ }^{8}$ Para las sillas francesas véase más abajo.
} 
un taburete a la francesa, pie de cabra, piernas traseras y delanteras, medio punto, moldado el respaldo y vaciado con tres faldones alrededor y adelante su zerchon y su chambrana a la inglesa con dos junquillos, y vaciada a bisel en medio, cuya pieza es una de las prevenidas en dichas ordenanzas del gremio de entallador y ensamblador (Doc. n. ${ }^{\circ}$ ).

Mientras que, como se advierte en el examen de Juan de León el 15 marzo 1744, una de las piezas acordadas para el examen de ebanista era:

un buro, que es un pie de papelera de tontillo cubierto de nogal por dentro e fuera y cintillado de naranjo con su basamento y tres cajones y los correspondientes dentro para escribania, cuya papelera es una de las prevenidas en dichas ordenanzas del gremio de ebanistas (Doc. n. ${ }^{\circ} 1$ ).

Lo normal es que en algunos casos los oficiales puedan acceder en un mismo examen a los dos oficios, si bien realizando dos pruebas, una de ebanista y otra de ensamblador, como en el caso de Pedro Verde en 1749:

En casa de Bustos debe cubrir unos tessteros de papelera del cuerpo de encima a la inglesa y en la de mi el dicho Manuel Sacristan un trasero de taburete de costilla con su copete moldado con concha encima, cuyas piezas son dos de las prevenidas en dichas nuestras ordenanzas de ebanistas (Doc. n. ${ }^{\circ}$ ).

Centrándonos solamente en estas dos décadas (1740-1760), podemos ofrecer un número de ebanistas y ensambladores con actividad manifiesta registrada notarialmente en la que se citan tres tipos de piezas, las que aún se conservan al gusto antiguo en algunas casas madrileñas, que son las registradas en los inventarios post mortem, las que están al uso en esos momentos, registradas en las cartas de dote y las últimas novedades, las que, por ser innovación, se entienden como piezas de examen.

A través de estos documentos se puede advertir, como apuntabamos al principio, la persistencia de muebles por parejas en inventarios, la continuación de las sillas o taburetes a la francesa, si bien desde 1744 a 1750 la pieza de examen de ensamblador - taburete a la francesa con pies de cabra con chambrana a la inglesa-, que se mantienen en 1758 ya como sillas a la inglesa con pies de cabra (M. López y J. Iglesias) o una silla con copete tallado con concha a la inglesa (Pedro Verde). La moda de los pies de cabra se inicia en Inglaterra, si bien es cierto se adopta rápidamente en toda Europa. Del mismo modo, otra de las piezas de examen, una mesa con pie de cabra con faldón a la inglesa de doblar con sus medios puntos en las esquinas en 1744 (Manuel Nicolás Suárez), que se repite igual en 1750 (Juan Pérez), responde claramente por su descrip- 
ción a las mesas de juego que se realizaban en Inglaterra en torno a 1720 . Aparte de una caja de tabaco a la inglesa (1751 Francisco Marcos), las cuatro piezas requeridas para el examen de ebanista son papeleras a la inglesa de medio punto con su cornisa moldada (1750 Monzón) o pies de papeleras al remedo de Inglaterra (1748 Juan López). Así, hasta la década de los setenta no comienzan a realizarse como piezas de examen muebles más cercanos a los franceses, cuando prácticamente toda Europa está ya inmersa en la corriente neoclásica.

CRONOLOGÍA DE LAS ACTIVIDADES DE lOS MAESTROS DEL GREMIO

Arranz, Juan

Maestro de arquitectura y ensamblador.

Vive en la calle de San Juan.

1744. 9 de enero: Junto con Miguel Serrano, maestro entallador, tasa los muebles y esculturas de doña Ana María de Soroa, entre los que se cuentan un retablo de oratorio y tres papeleras, dos de alambre y copetes, altas con tres cajones, valoradas en 3.000 rs. (Barrio Moya 1991: 171).

\section{Baltrán Martínez, Francisco}

Maestro de ebanistas.

1758, 20 de abril: Tasa los muebles de Blas de Beaumont, cirujano (Barrio Moya 1990a: 453).

\section{Bustos, Sebastiân de}

Maestro ebanista.

Con tienda en la calle de Fuencarral.

1748-1749: $\quad$ Examinador del gremio conjunto con Manuel Sacristán, ensamblador.

1763. 1 de diciembre: Tasa los muebles de Francisco Fernández de Samieles, consejero de Fernando VI y Carlos III (Barrio Moya 1990-II:695).

\section{Cermeño, Ambrosio}

Maestro ensamblador de nogal.

1741. 1 de julio: $\quad$ Recibe su carta de examen.

Examinadores: José Gregorio Hernández, maestro ebanista e Ignacio Tejero, maestro entallador y ensamblador.

Edad: 26 años. 
Pieza de examen: Un catre de nogal de dos varas y media de largo, dos varas de ancho y tres varas cumplidas de alto con sus cuatro tornillos a las esquinas y dos bisagras para doblarse por medio y su lecho correspondiente de tablilla y travesaños sus pies al medio con el juego de doblar?.

\section{Coyarga, Francisco Antonio}

Profesor de tallista y escultor.

Vive en la calle de las Huertas, casas de la Cofradía Sacramental y Ánimas de la iglesia parroquial de San Lorenzo.

1746. 22 de diciembre: Tasa las esculturas y muebles de Jose Gambazo, pintor (Barrio Moya 1997: 416) ${ }^{10}$.

\section{Delgado, Pedro}

Maestro entallador y ensamblador de nogal.

1748. 20 de octubre: Recibe su carta de examen.

Examinadores:

Manuel Sacristán, maestro entallador y ensamblador; Sebastián de Bustos, maestro ebanista.

Edad:

Aprendizaje:

Oficialía: 23 años.

Pieza de examen:

Con Manuel Sacristán durante 7 años.

En la misma casa-tienda.

Un arcón de nogal enlazado a lazo perdido ${ }^{11}$.

\section{Gavilanes, Vicente}

Ebanista.

1759, 14 de julio:

Tasa los muebles de Manuel de Ipenza, secretario de Fernando VI y Justicia del Tribunal de la Nunciatura. Destacan dos escritorios de concha, valorados en 5.500 rs. y dos papeleras de charol azul de Inglaterra en 3.600 rs. (Barrio Moya 1992: 640).

\section{Gómez, Francisco}

Maestro entallador y ebanista.

Vive en la collación de la Magdalena en casas de la Administración.

1755. 8 de enero:

Es nombrado tasador de los bienes de Josefa Pasero, mujer de Andrés Meléndez, tasación que realiza el 11 del mismo mes ${ }^{12}$.

\footnotetext{
9 A.H.P. Madrid. Protocolo 17.273, fol. 350.

${ }^{10}$ A.H.P. Madrid. Protocolo 15.234, s.f.

11 A.H.P. Madrid. Protocolo 15.353, fol. 204.

12 A.H.P. Madrid. Protocolo 17.880, fol. 14v.
} 


\section{Hernández, Francisco}

Maestro ebanista.

1751. 7 de mayo:

Tasa los bienes de Juan de Velasco, entre los que destaca una papelera a la inglesa cubierta de nogal con sus cristales y herrajes, en 840 rs. ${ }^{13}$

\section{Iglesias, Juan}

Maestro entallador y ensamblador de nogal. Muere antes de 1752.

1750, 15 de octubre: Recibe su carta de examen ${ }^{14}$.

Edad:

30 años, natural de Fuencarral.

Aprendizaje:

Con Diego Quintana.

Pieza de examen: Una silla a la francesa moldurada con pie de cabra y virachón adelante.

1752, 3 de noviembre: Su viuda Dionisia Ortega se casa con Francisco López, quien otorga su carta de pago y recibo de dote a su favor, incluyendo en ésta maderas y herramientas (Doc. n. ${ }^{\circ}$ ).

\section{León, Juan de}

Maestro ebanista.

Edad:

31 años, natural de Madrid.

1744, 15 de marzo: Recibe su carta de examen ${ }^{15}$.

Examinadores:

Manuel Rodríguez, maestro ebanista; Gabriel Muñoz, maestro entallador y ensamblador.

Aprendizaje: Con Gabriel Muñoz durante 6 años.

Pieza de examen:

Un buró (Doc. n. ${ }^{\circ} 1$ ).

\section{López, Gregorio}

Maestro entallador y ensamblador.

1749. 30 de marzo: Recibe su carta de examen ${ }^{16}$.

Examinadores: Manuel Sacristán y Sebastián de Bustos.

Pieza de examen: Cubrir tres gavetones grandes con un pie de papelera de Inglaterra a la inglesa.

\section{López, Juan}

Maestro ebanista.

1748, 20 de octubre: Recibe su carta de examen.

\footnotetext{
${ }^{13}$ A.H.P. Madrid. Protocolo 17.880.

${ }^{14}$ A.H.P. Madrid. Protocolo 15.353, fol. 759.

15 A.H.P. Madrid. Protocolo 15.341.

${ }^{16}$ A.H.P. Madrid. Protocolo 15.353, fol. 301.
} 
Examinadores: Sebastián de Bustos, maestro ebanista; Manuel Sacristán, maestro entallador y ensamblador.

Aprendizaje: Con Thomas de Prado, maestro ebanista hasta 1747 en que falleció Prado.

Oficialía: Tienda de María López, su madre.

Pieza de examen: Cubrir las bocas de una papelera a la inglesa de madera de nogal (Doc. n. ${ }^{\circ}$ 6).

Testigo: Baltasar Díaz, Manuel Serrano y Francisco Hernández ${ }^{17}$.

\section{López, Miguel}

Maestro ensamblador y entallador de nogal.

1744, 28 de diciembre: Recibe su carta de examen ${ }^{18}$.

Examinadores:

Manuel Rodríguez y Gabriel Muñoz.

Edad:

31 años, natural de Madrid.

Aprendizaje:

Con Gabriel Muñoz.

Pieza de examen:

Un taburete a la francesa, pie de cabra con chambrana a la inglesa (Doc. n. ${ }^{\circ}$ ).

1775:

Figura en la Lista de los individuos del Gremio de Ebanistas de Madrid.

\section{Marcos, Francisco}

Maestro entallador.

1751, 1 de mayo:

Edad:

Aprendizaje:

Pieza de examen:

Recibe su carta de examen ${ }^{19}$. 28 años, natural de Valladolid. Con Clemente Travieso y Antonio de Trueba. Una caja para tabaco a la inglesa de cuatro porciones para cuatro botes de a dos libras, maciza de nogal.

\section{Martín, Francisco}

Maestro ebanista.

1749, 18 de septiembre: Recibe su carta de examen ${ }^{20}$.

Edad: 45 años.

Examinadores:

Francisco Gómez, maestro ebanista; Matías Suárez, maestro entallador y ensamblador de nogal.

\footnotetext{
17 A.H.P. Madrid. Protocolo 15.353, fol. 202.

${ }^{18}$ A.H.P. Madrid. Protocolo 15.341, fol. 886.

19 A.H.P. Madrid. Protocolo 15.353, fol. 862.

${ }^{20}$ A.H.P. Madrid. Protocolo 15.353, fol. 407.
} 
Aprendizaje:

Pieza de examen:

\section{Mingo, Vicente}

Maestro ebanista.

1750, 18 de octubre:

Examinadores:

Edad:

Aprendizaje:

1775:

\section{Monzón, José}

Maestro ebanista. 1748, 19 de mayo:

Examinadores:

Edad:

Aprendizaje:

Oficialía:

Pieza de examen:
Pieza de examen:

Con José de Villacastín, maestro ebanista.

Cubrir de nogal los testeros de un tocadorcito.

Recibe su carta de examen ${ }^{21}$.

Francisco Gómez; Matías Suárez.

24 años, natural de Móstoles.

Con Francisco Gómez.

Papelera a la inglesa de medio punto con su cornisa moldada y alquitrabe toda ella cubierta de nogal.

Figura en la Lista de los individuos del Gremio de Ebanistas de esta Corte.

Recibe su carta de examen ${ }^{22}$.

Manuel Sacristán, maestro entallador y ensamblador; Sebastián de Bustos, maestro ebanista. 25 años.

Durante más de seis años, con Nicolás Monzón, su padre, maestro ebanista.

Diversos y fuera de la Villa con Antonio García y Sebastián García

Un pie de papelera cubierto de nogal al modo de Inglaterra.

\section{Muñoz, Gabriel}

Maestro entallador. 1744:

Veedor y examinador del gremio, no sabía firmar, según se constata en el examen de Juan de León ${ }^{23}$.

\section{Pérez, Juan}

Maestro ebanista.

1750, 15 de noviembre: Recibe su carta de examen ${ }^{24}$.

\footnotetext{
${ }^{21}$ A.H.P. Madrid. Protocolo 15.353, fol. 737.

${ }^{22}$ A.H.P. Madrid. Protocolo 15.353, fol. 24-25.

${ }^{23}$ A.H.P. Madrid. Protocolo 15.341, fol 798-99.

${ }^{24}$ A.H.P. Madrid. Protocolo 15.353, fol. 761.
} 
Edad:

Aprendizaje:

Pieza de examen:
35 años, natural de Madrid.

Con Manuel Sáenz.

Una mesa de doblar de juego, cubierta de nogal con sus pies de cabra.

\section{Rodriguez, Alfonso}

Ebanista.

1747, 21 de marzo: Tasa las alhajas de madera que el marqués de Villena, Mercurio Antonio López Pacheco, tenía en el castillo de Escalona (Barrio Moya 1989: 325) ${ }^{25}$.

\section{Rodriguez, Clemente Francisco}

Ebanista.

1757, 11 de enero:
Tasa, junto a Fernando Cuervo, maestro carpintero, los muebles de Miguel Sanz de Córdoba, secretario del Tribunal de la Inquisición. Destacan papelera, escritorios y sillas de Inglaterra junto con sillas a la española (Barrio Moya 1988: 621).

\section{Rodriguez, Manuel}

Maestro ebanista.

1744, 9 de noviembre: Junto con Gabriel Muñoz, maestro entallador y ensamblador, como veedores y examinadores del gremio, otorgan un poder a Diego Bernardino Garrido, Diego de Burgos y Antonio Pérez procuradores, ante el escribano Pedro de la Fuente ${ }^{26}$.

\section{Sacristán, Manuel}

Maestro entallador y ebanista.

Vive en la calle del Humilladero, en las casas que dicen de Zentani.

1742, 16 de octubre: Tasa las cosas de madera de Claudio Trabaca, artífice latonero ${ }^{27}$.

1746, 3 de noviembre: Junto con Manuel Tintero, carpintero, que vive en la carrera de San Jerónimo, valora los muebles de don Pedro Rosales y Medrano, consejero de Felipe $\mathrm{V}$ en el Consejo Real de Órdenes (Barrio Moya 1999: 1147).

\footnotetext{
${ }^{25}$ A.H.P. Madrid. Protocolo 14.855.

${ }^{26}$ A.H.P. Madrid. Protocolo 17.985, fol. 124.

${ }^{27}$ A.H.P. Madrid. Protocolo 17.276, fol. 3457.
} 


\section{Serrano, Miguel}

Maestro entallador. 1744, 9 de enero:

Tasa los muebles de doña Ana María Soroa.

Véase: Arranz, Juan.

\section{Suárez, Manuel Nicolás}

Maestro entallador y ensamblador.

1744, 2 de diciembre: Recibe su carta de examen ${ }^{28}$.

Edad:

22 años, natural de Granada.

Examinadores:

Manuel Rodríguez y Gabriel Muñoz.

Aprendizaje:

Con Manuel Moroncillo, dos años y medio, y tres años y medio con Manuel Rodriguez.

Pieza de examen: Una mesa de nogal de pies de cabra con su faldón a la inglesa, de doblar, con sus cuatro navetas y moldura alrededor, cubierta con su paño.

\section{Tintero, Manuel}

Maestro carpintero.

Vive en la Carrera de San Jerónimo.

1746 , de 45 años de edad.

Véase: Sacristán, Manuel.

\section{Travieso, Andrés}

Maestro ebanista.

Hijo de Clemente Travieso, maestro ebanista.

Aprendizaje: $\quad$ Con José Villacastín, maestro ebanista, seis años y medio.

Edad: 26 años, natural de Noceda.

1744, 30 de noviembre: Recibe su carta de examen (Doc. n. ${ }^{\circ}{ }^{2}{ }^{29}$.

Examinadores: Manuel Rodríguez y Gabriel Muñoz.

Pieza de examen: Un estante papelera de libros de dos varas con un cajón y cornisa.

1758, 17 de octubre: Valora los muebles de don Jose Ximénez, médico de Fernando VI (Barrio Moya 1995: 339), entre los que se cuentan taburetes o sillas a la inglesa, con patas de cabra, escaparates con cristales y papelera de caoba etc.

\footnotetext{
${ }^{28}$ A.H.P. Madrid. Protocolo 15.341, fol. 873.

29 A.H.P. Madrid. Protocolo 15.341.
} 
No figura en la Lista de ebanistas de esta Corte y sí, sin embargo, un Clemente y un Pedro Travieso.

\section{Travieso Rodriguez, Clemente}

Maestro ebanista y ensamblador.

1754, 12 de Julio:

Tasa la madera de Luis Berdot, vecino de Carabanchel de Abajo, jefe de ramillete de S.M. ${ }^{30}$

\section{Vandana, Pedro}

Maestro ebanista

1750. 18 de Julio

Examinadores:

Recibe su carta de examen ${ }^{31}$.

Edad:

Francisco Gómez y Matías Suárez.

Aprendizaje:

22 años.

Pieza de examen:

Con Gaspar Rodríguez.

Un pie de papelera con su puerta de caoba y huecos para gavetones y un cajón en la fachada armado en blanco.

\section{Verde, Pedro}

Maestro ebanista y ensamblador.

Natural de Segovia. 1749, 30 de marzo: Examinadores:

Aprendizaje:

Oficialía:

Pieza de examen:

Recibe su carta de examen (Doc. n. $\left.{ }^{0}{ }^{7}\right)^{32}$. Manuel Sacristán y Sebastián de Bustos. Con Diego Casado, maestro ebanista, durante seis años.

Varios maestros y Sebastián de Bustos.

Cubrir testeros de papelera a la inglesa (de ebanista) y trasero de taburete de costilla con su copete moldado con concha encima (de ensamblador).

1775

Figura en la Lista de ebanistas de esta Corte.

\section{Vivar, Esteban de}

Maestro entallador. 1749. 10 de agosto: Examinadores:

Recibe su carta de examen ${ }^{33}$.

Manuel Sacristán y Sebastián de Bustos.

\footnotetext{
${ }^{30}$ A.H.P. Madrid. Protocolo 17.880

31 A.H.P. Madrid. Protocolo 15.353, fol. 1.695.

32 A.H.P. Madrid. Protocolo 15.353, fol. 299-299v.

33 A.H.P. Madrid. Protocolo 15.353, fol. 573.
} 
Edad:

Aprendizaje:

Oficialía:

Pieza de examen:

35 años.

Con Pedro López, maestro ebanista, durante seis años.

Ocho años con varios.

Un atril de nogal de una pieza (con Manuel Sacristán). Un palo de nogal a escuadra (con Sebastián de Bustos).

\section{Verdugo, Francisco}

Maestro ebanista.

1753. 25 de septiembre: Otorga poder a procuradores para que se efectue el inventario de su mujer, Ana de Palomares ${ }^{34}$.

\section{DOCUMENTOS}

DOCUMENTO n. ${ }^{\circ} 1$

A.H.P. Madrid. Protocolo 15.341, fols. 798-779.

Carta de examen de maestro ebanista en favor de Juan de Leon.

1744,15 de marzo.

Sepan como nos Manuel Rodriguez, maestro de ebanista y Gabriel Muñoz, maestro entallador y ensamblador de nogal, veedores y examinadores de dichos dos gremios y artes, vecinos de esta villa de Madrid como tales y usando de la facultad que por razón de los oficios les es concedida y de la misma que han usado nuestros antecesores hallandose ejerciendo los mismos oficios y cargos; decimos que ante nos y el infrascripto escribano del numero, nuestro secretario parecio presente Juan de Leon natural y vecino desta dicha villa que es un mozo de edad de treinta años poco mas o menos de mediana estatura, pelo rubio, delgado, nariz grande con un lunar en el carrillo derecho, hijo legítimo de Juan de Leon y Melchora de Isla; y nos hizo relacion diciendo habia sido aprendiz tiempo de seis años y despues usado y ejercido el dicho arte de ebanista en diferentes tiendas de maestros de esta Corte de mas de siete años a esta parte a que habia sido y era inclinado y que ahora en fuerza de lo referido queria y nos suplicaba le examinasemos y aprobasemos del tal arte del gremio de ebanista para usarle y ejercerle por si solo por hallarse habil y suficiente para ello, y que hallando estarlo le diesemos su carta de examen del dicho arte en la forma ordinaria; en conformidad de lo qual y atento a constarnos de su habilidad y su ciencia, mediante haber estado por aprendiz en la casa de mi el dicho Gabriel Muñoz, en fuerza de contrata que para ello precedio y por espacio del y a dicho tiempo de seis años que se previenen en las ordenanzas, como asi lo juro por Dios nuestro señor y a una señal de cruz en forma ante el infraescripto nuestro secretario

${ }^{34}$ A.H.P. Madrid. Protocolo 18.520, fol. 144. 
en observancia y cumplimiento de lo acordado y determinado en punto de los que recibieren a examen en la junta que por ambos gremios se celebro en el dia cinco de diciembre del año pasado de mil setecientos cuarenta y tres. $Y$ atento a ser cierto publico y notorio que despues ha trabajado y ejercido dicho arte como tal oficial el tiempo de mas de los dichos siete años le admitimos a dicho examen el dia de la fecha y en el y para el le hicimos diferentes preguntas y repreguntas tocantes a dicho arte a que respondió a nuestra satisfacción habiendo hecho y ejecutado por nuestro mandado un buro, que es un pie de papelera de tontillo cubierto de nogal por dentro e fuera y cintillado de naranjo con su asamento y tres cajones y los correspondientes dentro para escribania, cuya papelera es una de las prevenidas en dichas ordenanzas del gremio de ebanistas; lo que ha ejecutado en toda perfección. Y vista por nos su habilidad y suficiencia y haberlo hecho conforme al arte, lo declaramos por bien ejecutado y por examinado y aprobado en el dicho arte de ebanista al referido Juan de Leon y le mandamos dar su carta de examen en la forma ordinaria en cuya virtud y de lo por nos acordado este dia, le damos la presente carta de examen de maestro ebanista y con ella poder, licencia y facultad para que como tal maestro examinado y aprobado se pueda usar y ejercer, use y ejerrza en esta corte y villa de Madrid como fuera de ella, en todas partes, ciudades, villas y lugares de estos reinos y señorios de S.M. sin incurrir en pena ni delito alguno y pedimos y suplicamos a todos y cualesquier jueces [...] use bien y fielmente el dicho arte de ebanista cuyo juramento le ha sido recibido por el presente escribano de que a nuestro pedimento da fe [...] en Madrid a quince dias del mes de marzo año de mil setecientos cuarenta y cuatro, siendo testigos Josep Rodriguez, Juan Francisco Lema y baltasar Diaz Nuñez residentes en esta corte y los dichos veedores y examinadores a quienes yo el infrascripto doy fe que conozco. Lo firmaron. Luego dijo Gabriel Muñoz no sabía firmar y a su ruego lo hizo uno de los dichos testigos.

Manuel Rodriguez Testigo a ruego Baltasar Diaz ante mi Tomás Franco. Figueroa.

DOCUMENTO $\mathrm{n} \cdot{ }^{\circ} 2$

A.H.P. Madrid. Protocolo 15.341, fols. 870-872.

Carta de examen de Maestro Ebanista de Andrés Travieso.

1744, 30 de noviembre.

Sepase como nos Manuel Rodriguez maestro dde ebanista y Gabriel Muñoz, entallador y ensamblador de nogal, beedores y examinadores de dhos dos gremios y artes vecinos de esta villa de Madrid como tales y usando de la facultad que por razon de nuestros oficios nos es concedida y de la misma que han usado nuestros antecesores hallandose ejerciendo los mismos oficios y cargos, decimos que ante nos y el infrascripto escribano de numero nuestro secretario, parecio presente Andres Trabieso, vecino desta dicha villa y natural de la de Noceda que es un mozo de edad de ventiseis años poco mas o menos de mediana estatura, carirredondo, barbinegro, ojos grandes, un poco patiestebado, hijo legitimo de Clemente Travieso y de Maria Alvarez y nos hizo relacion diciendo habia sido aprendiz tiempo de seis años y medio, y despues usado y ejercido, y actualmente estaba usando y ejerciendo el dicho arte de ebanista demas de tres años y medio desta parte a que habia sido y hera 
inclinado y que ahora en fuerza de lo referido queria y nos suplicaba le examinasemos y aprobasemos de tal arte del gremio de ebanista para usarle y ejercerle por si solo por hallarse abil y suficiente para ello y que hallando estarlo le diesemos su carta de examen del dicho arte en la forma ordinaria y en conformidad de lo qual y attento a contarnos de su habilidad y suficiencia mediante haber estado de aprendiz en la casa de Joseph Villacastin, maestro del dicho, ebanista en esta Corte en fuerza de contrata que para ello precedio y por espacio del ya dicho tiempo de seis años y medio que se previenen en los capitulos de nuestras ordenanzas como asi nos consta, y a mayor abundamiento lo ha jurado el referido Joseph Villacastín antes de ahora por Dios nuestro señor y a una señal de cruz en forma a nuestra presencia y ante el dicho nuestro secretario a quien le pedimos que de ello de fé; yo el infrascripto la doy de su certidumbre; lo qual a efectuado dicho Joseph en observancia y cumplimiento de lo acordado y determinado en punto de los que recurren a examen en la junta que para ambos gremios se celebro el dia cinco de diciembre del año proximo pasado de setecientos cuarenta y tres;

$\mathrm{Y}$ atento a ser publico y notorio que despues ha trabajado y ejercido dicho arte como tal oficial el tiempo de mas de los dichos tres años y medio, le admitamos a dicho examen, hoy dia de la fecha y en el y para el le hicimos diferentes preguntas y repreguntas tocantes al citado arte a que respondio a nuestra satisfaccion, habiendo hecho y ejecutado por nuestro mandado un estante papelera de libros de dos varas y vara y cuarto de ancho, media vara de fondo con su basa, sotabasa y en el hueco que hace el, presenta un cajon a modo de mocheta que forma su media uña, una puerta armada de inglete con un medio punto tirado en el medio a la parte de arriba y en ella misma moldado un quarta bocel adentro y afuera y encima un arquitrabe y cornisa y por pies de dicha papelera unas cartelas en escuadra acarteladas y enlazadas y en dentro de la citada papelera cuatro entrepaños engargolados, toda ella de madera de aliso; cuya pieza es una de las prevenidas en las ordenanzas del gremio de ebanistas, la que ha ejecutado en toda perfeccion y vista por nos su habilidad y suficiencia y haberlo hecho conforme al arte, lo declaramos por bien ejecutado y por examinado y aprobado en el dicho arte de ebanista al referido Andres Travieso y le mandamos dar su carta de examen en la forma ordinaria en cuya virtud y de lo por nosotros acordado este dia le damos la presente carta de examen de maestro de ebanista, y con ella poder, licencia y facultad para que como tal maestro examinado y aprobado le pueda usar y ejercer, use y ejerza asi en esta Corte y Villa de Madrid como fuera della en todas partes, ciudades, villas y lugares de estos reinos y señorios de Su Majestad, sin incurrir en pena ni delito alguno y pedimos y suplicamos que todos y qualesquier señores, jueces y justicias de su magestad de qualesquier partes que sean, hallen y tengan al dicho Andres Travieso por tal maestro examinado y aprobado en dicho arte de ebanista como lo es y esta y se le deje usar y ejercer. El qual que presente esta en conformidad de nuestras ordenanzas y esta la practicada en dichos nuestros gremios y artes y uso de su libre y espontanea voluntad y Dios Nuestro Señor y a una señal de la cruz según forma de derecho usar bien y fielmente el dicho arte de ebanista cuyo juramento tambien le ha sido recibido por el presente escribano, de que a nuestro pedimento da fe;

Atento a lo qual le damos esta carta que en su favor otorgamos de la que pedimos a dicho presente escribano le de y entregue traslado signado y firmado en esta villa de Madrid a treinta dias del mes de noviemnbre año de mil setecientos cuarenta y cuatro; ante el escribano del numero a quien doy fee conozco, siendo testigo Gabriel 
Tejero, Alvaro Garrido y Baltasar Diaz Martinez, residentes en esta Corte y de los dichos veedores y examinadores a quienes yo el infrascripto da fee conozco, lo firmo el que supo y por el que no uno de los dichos testigos

Manuel Rodriguez Testigo a ruego Baltasar Diaz Martinez

Ante mi Thomas Franco Izquierdo

Como tesorero que soy de el patriarca san Joseph he recibido de los Ss. Manuel Rodriguez y Gabriel Muñoz beedores de los hebanistas desta Corte ziento y treinta y ocho reales de vellon, los ziento y treinta y dos que pertenecen a el santo y los seis para el mullidor y lo firme en Madrid a 13 de diciembre de 1744

$\mathrm{Y}$ es del examen de Andres Travieso. Simon Cabeza

DOCUMENTO N. ${ }^{\circ} 3$

A.H.P. Madrid. Protocolo 15.341, fols. 873-874.

Carta de examen de maestro entallador y ensamblador de Manuel Nicolás Suarez.

1744, 2 de diciembre.

Sepan como nos Gabriel Muñoz, maestro entallador y ensamblador de nogal y Juan Rodriguez, maestro de ebanista, veedores y examinadores de dichos gremios y artes, vecinos desta villa de Madrid como tales usando de la facultad que por razon de nuestros oficios nos es concedida y de la misma que han usado nuestros antecesores, hallandose ejerciendo los mismos oficios y cargos; decimos que ante nos y el infrascripto escribano del numero, nuestro secretario, parescio presente Manuel Nicolas Suarez, natural de la ciudad de Granada y vecino al presente en esta dicha villa, que es un mozo de edad de veinte y dos años poco mas o menos, de mediana estatura y cuerpo, pelo negro, nariz pequeña y ancha y una cicatriz sobre el ojo izquierdo, hijo legitimo de Juan Antonio Suarez y de Catalina de Herrera Nazareno; y nos hizo relacion diciendo que habia sido aprendiz tiempo de seis años y despues usado y ejercido y actualmente estaba usando y ejerciendo el dicho arte de entallador y ensamblador de nogal en distintas tiendas de tallas de esta corte demas de un año a esta parte a que habia sido y era inclinado y que ahora en fuerza de lo referido, queria y nos suplicaba lo examinasemos y aprobasemos del tal arte de entallador y ensamblador para usarle y ejercerle por si solo por hallarse habil y suficiente para ello [...] haber estado de aprendiz en casa de Manuel Rodriguez tiempo de dos años y medio, como en casa de Manuel Moroncillo tiempo de tres años y medio, ambos maestros del dicho gremio y arte de ensambladores [...] que recibieron a examen en la junta que por ambos gremios se celebro el dia cinco de diciembre del año proximo pasado de mil setecientos cuarenta y tres [...] le admitimos a examen hoy dia de la fecha y en el y para ello hicimos diferentes preguntas y repreguntas tocantes al dicho arte a que respondio a nuestra satisfaccion, habiendo hecho y ejecutado por nuestro mandado una mesa de pies de cabra con su faldon a la inglesa de doblar con sus cuatro medios puntos a los esquinazos con sus cuatro navetas y moldura alrededor, cubierta con su paño, cuya pieza es de nogal y una de las prevenidas en las dichas ordenanzas del gremio de entalladores y ensambladores, lo que ha ejecutado con toda perfeccion [...] lo declaramos por examinado y aprobado en el dicho arte [...] y le 
damos su carta de examen para que como maestro examinado y aprobado lo pueda ejercer en esta Corte y Villa de Madrid, como fuera de ella...

Testigos Baltasar Diaz Martinez, Alfonso Alvarez y Julian Antonio Herreros, residemtes en esta Corte y de los beedores y examinadores a quienes yo el infrascripto doy fee conozco, lo firmo el que supo y por el que no un testigo a su ruego

Manuel Rodriguez Testigo a ruego Baltasar Diaz

Ante mi Thomas Francisco Izquierdo

DOCUMENTO N. ${ }^{\circ} 4$.

A.H.P. Madrid. Protocolo 15.341, fol. 886.

Carta de examen de maestro entallador y ensamblador Miguel López.

1744,28 de diciembre.

Sepan como nos Gabriel Muñoz maestro entallador y ensamblador de nogal, y Manuel Rodriguez maestro de ebanista, behedores y examinadores de dichos dos gremios y artes y vecinos de esta villa de Madrid como tales y usando de la facultad que por razon de nuestros oficios nos es concedida y de la misma que han usado nuestros antecesores, hallandose ejerciendo los mismos oficios y cargos, decimos que ante nos y el infrascritto escribano de numero, nuestro secretario pareció presente Miguel Lopez natural y vecino de esta villa que es un mozo de edad de treinta y un años poco mas omenos de buena estatura, pelo castaño, un poco grueso, y romo y pintado de viruelas, hijo legitimo de Isidro Lopez y de Maria Cañedo, y nos hizo relación diciendo habia sido aprendiz tiempo de seis años, y despues usado y ejercido y actualmente estaba usando y ejerciendo el dicho arte de entallador y ensamblador de nogal en diferentes tiendas de maestros de esta corte, de mas de cuatro años a esta parte, a que habia sido y era inclinado, y que ahora en fuerza de lo referido, queria y nos suplicaba le examinaramos y aprobaramos del tal arte del gremio de entallador y ensamblador de nogal para usarle u ejercerle por si no solo hallarle habil y suficiente para ello, y que hallando estarlo le diesemos su carta de examen del citado arte en la forma ordinaria, en conformidad de lo cual y atento a constarnos de su habilidad y suficiencia, mediante haber estado por aprendiz en la casa del dicho Gabriel Muñoz, en fuerza de contrata que para ello precedio y por espacio del referido tiempo de seis años que se previenen en los capitulos de nuestras ordenanzas como asi lo juro por Dios nuestro señor y a una señal de la cruz en forma [...] en cumplimiento de lo acordado y determinado en punto de los que recibiesen a examen en la Junta que por ambos gremios se celebro en el dia cinco de diciembre del año proximo pasado de mil setecientos cuarenta y tres, y atento a ser cierto, publico y notorio que despues ha trabajado y ejercido dicho arte de entallador y ensamblador como tal oficial el tiempo de mas de los mencionados cuatro años, le admitimos a dicho examen, hoy dia de la fecha y en el y para el le hicimos diferentes preguntas y repreguntas tocante a dicho arte a que respondió a toda satisfacción habiendo hecho y ejecutado por nuestro mandado un taburete a la francesa, pie de cabra, piernas traseras y delanteras, medio punto, moldado el respaldo y vaciado con tres faldones alrededor y adelante su zerchon y su chambrana a la inglesa con dos junquillos, y 
vaciada a bisel en medio, cuya pieza es una de las prevenidas en dichas ordenanzas del gremio de entallador y ensamblador lo que ha ejecutado en toda perfeccion. Y vista por nos su habilidad y suficiencia y haberlo hecho conforme al arte lo declaramos por bien ejecutado y por examinado y aprobado en el dicho arte de entallador y ensamblador a el referido Miguel Lopez; y le mandamos dar su carta de examen en la forma hordinaria en cuya virtud y de lo por nos acordado este dia, le damos la presente carta de examen de maestro entallador y ensamblador de nogal y con ella poder, licencia y facultad para que como tal maestro examinado y aprobado le pueda usar y ejercer y use y ejerza asi en esta corte y villa de Madrid como fuera de ella en todas partes, ciudades villas y lugares de estos reinos y señorios de su Majestad sin incurrir en pena ni delito alguno y pedimos u suplicamos a todos y quales quier señores jueces y justicias de su majestad de qualesquier partes que sean; digan y tengan al dicho Miguel Lopez por tal maestro examinado y aprobado en el dicho arte de ebanista digo entallador y ensamblador, como lo es y esta jue ledese [sic] use y ejerzca igual que presente esta en conformidad de nuestras ordenanzas y estilo practicado en dichos nuestros gremios y artes. Juro de su libre y espontanea voluntad por Dios nuestro Señor y a una señal de la cruz segun forma de derecho usar fielmente el dicho arte de entallador y ensamblador; cuyo juramento le ha sido recibido por el presente escribano [...] fecha en Madrid a beinte y ocho dias del mes de diciembre año de mil setecientos cuarenta y cuatro siendo testigos Baltasar Diaz Alphonso Albarez y Domingo German residentes en esta corte. Los dichos veedores y examinadores a quien yo el infrascrito doy fe que conozco [...] Manuel Rodriguez, Baltasar Diaz . Ante mi Tomas Franco. Izquierdo.

Como tesorero que soy del patriarca san Joseph, recibí de los señores Manuel Rodriguez y Gabriel Muñoz, veedores del gremio de ensambladores de nogal, ciento y treinta y ocho reales de vellon por el examen de Miguel Lopez y son los ciento y treinta y dos r.v. que corresponden al sto y los seis para el mullidor: y lo firme en Madrid a 27 de diciembre de 1744. Simon Cabeza.

DOCUMENTO N. ${ }^{\circ} 5$.

A.H.P. Madrid. Protocolo 15.353, fols. 24-25.

Carta de examen de maestro ebanista de Joseph Monzon.

1748,19 de mayo.

Sepan como nos Sebastian de Bustos maestro de ebanista y Manuel Sacristan maestro entallador y ensamblador de nogal. Veedores y examinadores de dichos dos gremios y artes, vecinos deesta villa de Madrid, como tales y usando de la facultad que por razón de nuestros oficios nos es concedida y de la misma que han usado nuestros antecesores hallandose ejerciendo los mismos oficios, decimos que ante nos y el infrascrito escribano del numero nuestro secretario parecio presente Joseph Monzon natural y vecino de esta villa de edad veinte y cinco años, mediana estatura moreno de rostro barbinegro, con una cicatriz en la mano izquierda junto a la muñeca, hijo de Nicolas Monzon y de Maria sus padres; y nos hizo relacion diciendo habia sido aprendiz tiempo de mas de seis años y medio y despues ejercido y actualmente estaba ejerciendo el dicho arte de ebanista de mas de ocho años a esta parte a que era 
inclinado; en fuerza de lo cual queria y nos suplicaba le examinasemos y aprobasemos del tal arte del gremio de ebanistas para usarle por hallarse habil para ello y que hallando estarlo le diesemos su carta de examen en la forma ordinaria, en cuya conformidad yatento a constarnos su habilidad y suficiencia por haber estado de aprendiz en la casa tienda y compañia del referido Nicolas Monzon su padre que fue de ebanista en esta Corte por espacio de los dichos seis años y medio mas de los que se previenen en los capitulos de nuestras ordenanzas; y posterior a esto haber trabajado como oficial dicho arte de ebanista tiempo de mas de los mencionados ocho años, en diferentes tiendas de maestros del referido arte en esta Corte y ultimamente fuera de esta dicha villa con Antonio Garcia y Sebastian Garcia; como todo es cierto publico y justificativo; le admitimos al citado examen hoy dia de la fecha y para el le hicimos diferentes preguntas y repreguntas tocante al citado arte a que respondió a nuestra satisfacción, habiendo hecho de nuestro mandado un pie de papelera cubierto de nogal al remedo de Inglaterra cuya pieza es una de las prevenidas en las enunciadas ordenanzas de ebanistas, la que ha ejecutado en toda perfeccion; vista por nos su habilidad y suficiencia y haberla hecho conforme al arte le declaramos por bien ejecutado y por examinado y aprobado en el dicho arte de ebanista al referido Joseph Monzon y le mandamos dar su carta de examen en la forma ordinaria; en cuya virtud y de lo por nos acordado este dia le damos la presente carta de examen de maestro de ebanista y con ella poder licencia y facultad para que como tal maestro examinado y aprobado le pueda usar y ejercer, use y ejerza ansi en esta Corte y Villa de Madrid como fuera de ella en todas partes, ciudades, villas y lugares de estos reinos y señorios de S.M. sin incurrir en pena ni delito alguno y pedimos y suplicamos a todos y qualesquier señores jueces y justicias de S.M. de qualesquier parte que sean hayan y tengan a dicho Joseph Monzon por tal maestro examinado y aprobado en el referido arte de ebanista como lo es y esta, y se le dejen usar y ejercer, el qual que presente se halla en conformidad con nuestras ordenanzas y estilo practicado en dichos nuestros gremios y artes juro de su libre y espontanea voluntad por Dios nuestro Señor y a una señal de cruz segun forma e derecho usar bien y fielmente el dicho arte de ebanista, cuyo juramento tambien le ha sido recibido por el presente escribano de que a nuestro pedimento da fe, atento a lo cual le damos esta carta que a su favor otorgamos de la que pedimos a dicho infraescrito le de y entregue traslado signado y firmado, fecha en Madrid a diez y nueve dias del mes de mayo año de mil setecientos cuarenta y ocho siendo testigos Francisco Hernandez, Manuel Serrano y Baltasar Diaz Martinez, residentes en esta Corte y los dichos veedores y examinadores a quienes doy fe conozco lo firmaron: Sebastian de Bustos, Manuel Sacristan ante mi Tomas Francisco Izquierdo.

Digo yo Francisco Gomez, como tesorero que soy de la Cofradia del glorioso Patriarca San Joseph, que recibi de Joseph Monzon ciento y treinta y dos reales de vellon, los mismos que pertenecen a dicha Cofradía por su examen mas los seis reales de vellon para el mullidor, que componen dichas dos parrtidas ciento y treinta y ocho reales y por la verdad lo firme a 21 de abril de 1748 años. Son 138 reales de vellon. Franco Gomez. 
DOCUMENTO N. ${ }^{\circ} 6$.

A.H.P. Madrid. Protocolo 15.353, fols. 202-203.

Carta de examen de maestro ebanista de Juan Lopez.

1748,20 de octubre.

Sepan como nos Sebastian de Bustos maestro de ebanista y Manuel Sacristan maestro entallador y ensamblador de nogal. Veedores y examinadores de dichos dos gremios y artes unidos deesta villa de Madrid, como tales y usando de la facultad que por razón de nuestros oficios nos es concedida y de la misma que han usado nuestros antecesores hallandose ejerciendo los mismos oficios, decimos que ante nos y el infrascrito escribano del numero nuestro secretario parecio presente Juan Lopez natural y vecino de esta villa de edad de diez y nueve años, mediana estatura delgado de cuerpo, moreno de rostro con algunas señales de viruelas, ojos pequeños, pelo negro, hijo legitimo de Pedro Lopez difunto y natural que fue de casarrubios del Monte y de Maria Alonso que lo es de la villa de Valdemoro, y nos hizo relacion diciendo habia sido aprendiz y ejercido desde su tierna edad y actualmente estaba ejerciendo el dicho arte de ebanista a que era inclinado; en fuerza de lo cual queria y nos suplicaba le examinasemos y aprobasemos del tal arte del gremio de ebanistas para usarle por hallarse habil y que estandolo le diesemos su carta de examen en la forma ordinaria, en cuya inteligencia y atento a constarnos su habilidad y suficiencia mediante haber estado por aprendiz en la casa tienda de Tomas de Prado maestro ebanista que fue en esta Corte, desde la edad de doce años hasta el proximo pasado en que murio dicho Prado y despues trabajado como oficial en la casa tienda que al presente tiene dicha Maria Alonso su madre, tiempo de mas de lo que previenen las ordenanzas de dichos nuestros gremios, segun que asi le consta a todos y es publico y notorio, le admitimos al citado examen hoy dia de la fecha y para el le hicimos diferentes preguntas y repreguntas tocantes al citado arte, a que respondio a nuestra satisfacción haviendo hecho de nuestro mandado el cubrir las bocas de una papelera a la inglesa de madera de nogal cuya pieza es una de las prevenidas en las enunciadas ordenanzas de ebanistas y la ha ejecutado en toda perfeccion. Y vista por nos su habilidad y suficiencia y estar hecha conforme al arte, lo declaramos por bien ejecutado y por examinado y aprobado en el dicho arte de ebanista al referido Juan Lopez y le mandamos dar su carta de examen en la forma ordinaria; en cuya virtud y de lo por nos acordado este dia le damos la presente carta de examen de maestro de ebanista y con ella poder licencia y facultad para que como tal maestro examinado y aprobado le pueda usar y ejercer, use y ejerza ansi en esta Corte y Villa de Madrid como fuera de ella en todas partes, ciudades, villas y lugares de estos reinos y señorios de S.M. sin incurrir en pena ni delito alguno y pedimos y suplicamos a todos y qualesquier señores jueces y justicias de S.M. de qualesquier parte que sean hayan y tengan a dicho Juan Lopez por tal maestro examinado aprobado en el referido arte de ebanista como lo es y esta, y se le dejen usar y ejercer, el qual que presente se halla en conformidad con nuestras ordenanzas y estilo practicado en dichos nuestros gremios y artes, juro de su libre y espontanea voluntad por Dios nuestro Señor y a una señal de cruz segun forma e derecho usar bien y fielmente el dicho arte de ebanista, cuyo juramento tambien le ha sido recibido por el presente escribano de que a nuestro pedimento da fe; atento a lo cual le damos esta carta que a su favor otorgamos de la que pedimos a dicho infraescrito le de y entregue traslado signado y firmado, fe- 
cha en Madrid a veinte dias del mes de octubre de mil setecientos cuarenta y ocho siendo testigos Baltasar Diaz Martinez, Manuel Serrano y Francisco Hernandez residentes en esta Corte y los dichos veedores a quienes doy fe conozco lo firmaron: Sebastian de Bustos, Manuel Sacristan ante mi Tomas Francisco Izquierdo.

DOCUMENTO N. ${ }^{\circ} 7$.

A.H.P. Madrid. Protocolo 15.353, fol. 299-299v.

Carta de examen de Maestro ebanista de Pedro Verde.

1749, 30 de marzo.

Sepan como nos Sebastian de Bustos, maestro ebanista y Manuel Sacristan maestro entallador y ensamblador de nogal, veedores y examinadores de dichos dos gremios y artes vecinos de esta villa de Madrid y como tales y usando de la facultad que por razon de nuestros oficios nos es concedida y de la misma que han usado nuestros antecesores hallandose ejerciendo los mismos oficios, decimos que ante nos y el infrascripto escribano del numero parecio presente Pedro Verde, natural de la ciudad de segovia, y ahora residente en esta Corte, de edad de veinte y dos años, blanco de rostro, pelo y barba rubia cenceño cariaguileño con una cicatriz cruzada en medio de la frente, y nos hizo relacion diciendo habia sido aprendiz tiempo de seis años y despues ha ejercido y actualmente estaba ejerciendo el dicho arte de ebanista tres años, a que era inclinado en fuerza de lo cual queria y nos suplicaba le examinasemos y aprobasemos del tal arte de ebanista para usarle por si solo por hallarse habil, y que estandolo le diesemos su carta de examen en la forma ordinaria; en cuya inteligencia y atento a constarnos su habilidad y suficiencia mediante haber estado por aprendiz en la casa tienda de Diego Casado dichos seis años, que son los que previenen nuestras ordenanzas, como asi lo jura a Dios y a una señal de cruz en forma de derecho el enunciado Diego Casado maestro de ebanista en esta Corte, que presente se halla de que el infrascrito escribano del numero secretario de dichos gremios y artes da fe; y despues trabajado como oficial en diversas partes y con distintos maestros de esta Corte, tiempo de tres años y actualmente en casa de mi dicho Sebastian de Bustos: a el nominado ejercicio de ebanista segun que asi consta a todos y es publico y notorio: le admitimos al citado a examen hoy dia de la fecha y para el le hicimos diferentes preguntas tocantes al dicho arte, a que respondio a nuestra satisfacción habiendo hecho de nuestro mandado en casa de mi el referido Bustos el cubrir unos tessteros de papelera del cuerpo de encima a la inglesa y en la de mi el dicho Manuel Sacristan un trasero de taburete de costilla con su copete moldado con concha encima, cuyas piezas son dos de las prevenidas en dichas nuestras ordenanzas de ebanistas y las ha ejecutado en toda perfección. y vista por nos su habilidad y suficiencia y estar hechas conforme al arte lo declaramos por bien ejecutado y examinado y aprobado en dicho arte de ebanista al referido Pedro verde y le mandamos dar su carta de examen en la forma ordinaria, en cuya virtud y de lo por nos acordado le damos la presente de maestro de ebanista y con ella poder, licencia y facultad para que como tal maestro examinado y aprobado le pueda usar y ejercer use y ejerza asi en esta corte y villa de maderid como fuera de ella en todas partes villas y ciudades $[\ldots]$ 
DOCUMENTO N. ${ }^{\circ} 8$

A.H.P. Madrid. Protocolo 17.276, fol. 3.459.

Manuel Sacristan maestro entallador tasa las cosas de madera de Claudio Trabaca, artifice latonero.

1742, 16 de octubre.

Manuel Sacristan, maestro entallador y ebanista en esta corte que vive en la calle del Humilladero, casas que dicen de Zentaní [...] En primer lugar dos escriptorios cubiertos de concha y perfilados de hueso con cuatro navetas a lo alto, perspectivas en el dentro y corredores de bronze y mesas de nogal correspondientes en [...] 1080 reales vellon.

- Dos urnas de concha y ebano de una vara de alto y tercia de fondo con corredores de bronce y divisiones de concha en los vidrios doze septales chicos delante y en los costados y uno grande en medio de la fachada con sus mesas correspondientes [...] 1100 rs.

- Dos espejos de luna de dos tercias de alto con marcos de peral de vara de alto y tres cuartas de ancho guarnecidos con adornos y copetes de metal dorado demolido en [...] 600 rs.

- Una barrera de caoba fresada de ebano con su corredor de bronce y los escudos en la puerta.

- Un arcon de nogal pies cebollones moldura y basa, aldabones y cantoneras de hierro con un cajon y dos navetas [...] 36 rs.

- Un arcon de caoba [...] 330 rs.

- Un cofre de baqueta [...].

- Una mesa de nogal con cajon de pino y pies torneados.

- Una mesa redonda de doblar de pino, pintados los pies de encarnado.

- Seis taburetes a la francesa con copete de nogal guarnecidos de tachuela blanca y galon de seda azul con asientos y respaldos de gamuza encarnada y cubiertas de guadamacil labrado a 54 cada uno [...] 324 rs.

- Seis sitiales compañeros de nogal torneado a 18 rs.

- Un tocador cubierto de concha y cordoncillo alrededor de palosanto y rosa con mesa correspondiente [...] 120 rs.

- Una cama de colgar de palosanto bronceado de molido [...] 600 rs.

- Un biombo de ocho hojas ordinario [...] 60 rs.

DOCUMENTO N. ${ }^{\circ} 9$.

A.H.P. Madrid. Protocolo 18.520, fols. 63-65v.

Carta de Pago y recibo de dote otorgada por Francisco López a favor de Dionisia Ortega. 1752, 3 de noviembre.

Sepase por esta publica escriptura de carta de pago y recivo de dote vieren como yo Francisco Lopez hijo lexitimo de Francisco Lopez difunto y de Magdalena Serrano vecinos de esta villa Digo que [...] estoy tratando de desposarme, casarme [...] con Dionisia de Ortega viuda de Juan de Iglesias vecino y maestro de evanista que fue en esta corte, hija legitima de Patricio Ortega y de Maria Escribano vecinos de la villa de Añober de este arzobispado, la qual para subvenir a las cargas del matrimonio 
trahe a el diferentes vienes muebles como son vestidos, ropa blanca madera para el exercicio de evanista y otros trastos menaxe de cassa los que le quiere entregar con tal que primero y ante todas cosas otorgarle a su favor la correspondiente carta de pago y viendo que es justa su pretension y que con ello estoy obligado poniendolo en execucion otorgo que recivo de mano de la dha Dionisia Ortega mi futura esposa los bienes siguientes.

Herramientas:

Primeramente un banco de serrar madera tasado en cincuenta rs. de vellon [...] 50 rs. Un banco de nogal de dos tercias de ancho tasado en quarenta y cinco rs [...] 45.

Otro banco mas pequeño en [...] 22.

Tres Prensas correspondientes a el mismo exercicio de evanista todas en [...] 75 rs. Tres Barletes todos en [...] 36 rs.

Un tornillo y una bigornia en [...] 45 rs.

Quatro azuelas todas en [...] 28 rs.

Una sierra bracera en treinta y tres rs [...] 33 rs.

Dos sierras chicas y un serrucho y una sierra de trastos en diez y ocho r. 18.

Una docena de barrenas chicas y grandes en trece rs [...] 13.

Unas tixeras de cortar baqueta en [...] 5 rs.

Tres pares de tenazas en [...] 18.

Otro par de tenazas grandes en 6.

Veinte gubias chicas y grandes en [...] 30 rs.

Diez escoplos en [...] 20.

Diez formones a real y medio cada uno [...] 15 rs.

Cinco cepillos a dos rs y medio cada uno [...] 12 rs.

Veinte y quatro herramientas de moldar a tres rs. cada una [...] 72.

Ocho escofinas entre buenas y medianas en treinta y dos reales [...] 32.

De esquadras, cartabones, plantillas y otras menudencias en quince rs [...] 15.

Tres garlopas y dos junteras a diez rs [...] 50.

Un cazo para cola en quince rs [...] 15.

Un cepillo de dientes herrado en [...] 12 rs.

Oro cepillo de dientes quatro tornillos de madera y un filomoquete, todo en [...] 12 rs.

Madera.

Una docena de taburetes bajos de costilla sin guarnecer a veinte y quatro rs cada uno [...] 288

Cinco taburetes altos de costillas con los copetes tallados sin guarnecer a dos pesos cada uno hacen [...] 150.

Otras dos sillas de madera a la francesa en sesenta rs [...] 60.

Seis piezas de diferentes muestras a diez y ocho rs cada uno hacen [...] 108 rs.

Docena y media de taburetes de campaña de tijera en blanco a once rs cada uno [...] 198 rs.

Un tablon con dos tablas de largo y medio y tres quartas y media de ancho que compone diez quartones y medio en ciento y cinco rs [...] 105.

Otra de dos tercias tambien serrado que compone seis quartones y medio en [...] 75 rs.

Diez docenas y media de tablas de a siete, a quarenta y quatro reales la docena en quatrocientos sesenta y dos [...] 460.

Cinco tablas de nogal a quince rs cada una [...] 75 rs.

Treinta quartones de nogal a siete rs [...] 150. 
Madera cortada para docena y media de taburetes de costilla a seis reales cada uno [...] 108.

De diferentes retales de madera sesenta [...] 60 rs.

De despojos de madera fina [...] 50 rs.

Una cabezera de nogal rehelebada con su en medio en quince rs [...] 15 .

Tres tornillos de madera en seis [...] 6.

De piedras de afilar blancas y negras quince reales [...] 15 .

Una docena de sillas a seis reales cada una setenta y dos rs [...] 72 .

Quarenta y un lechos y medio a nuebe reales y medio cada uno importan [...] 120 rs. Un Catrecillo de tijera en [...] 17 rs.

Doce arrobas de pelote a quatro rs cada una, quarenta y ocho [...] 48.

De quatro arrobas de casca veinte y un rs [...] 21 rs.

Quince quartones de madera de alamo y otrras cosas a siete rs cada uno hacen ciento $\mathrm{y}$ cinco $[. .] 105$.

Un arcon de nogal de siete pies de largo con dos cerraduras y llaves en seiscientos rs [...] 600 rs.

Cinco maderas de cordel, dos lienzos de catre y una pieza de cincha todo en noventa rs [...] 90 .

Dos libras de zerda en ocho rs [...] 8 .

Cinco quartones de madera en [...] 35 rs.

Un sitial con una papelera en [...] 30 rs.

Dos taburetes a la ynglesa en [...] 30 rs.

Un bufete una papelerilla de nogal y concha en [...] 30 rs.

Un candado con su llabe en [...] 15 rs.

Media docena de copetes tallados en [...] 36 rs.

Ocho docenas de correas [...] 36 rs.

Catorce bastidores en quince rs [...] 15

Quarenta y ocho rs en que se baluaron diferentes clabos de clabazon [...] 48 .

Una caxita de calentador [...] 5 rs.

De diferentes quadros y pinturas [...] 60 rs.

Quarenta y ocho vidrios en [...] 48.

Una cama de cinco tablas en [...] 30 rs.

[...] de tornillos de sillas aldabas y tornillos de catres veinte rs [...] 20.

[...] siguen vestidos [...] importan la madera y los vestidos 2537 reales y 23 mrs.

Creditos y demas segun como ba expresado ocho mill ochocientos veinte y quatro rs $\mathrm{y}$ seis mrs.

DOCUMENTO N. ${ }^{\circ} 10$.

A.H.P. Madrid. Protocolo 15.353, fol. 875.

Poder General para pleitos que otorgaron los veedores y examinadores de los Gremios $y$ Artes unidos de maestros de ebanistas y ensambladores de nogal de esta corte a favor de procuradores.

1751,9 de julio.

En la villa de Madrid a nueve dias del mes de julio año de mil setecientos cincuenta y uno; ante mi el escribano y testigos, parecieron Francisco Gomez, maestro 
de ebanista y Matias Suarez, maestro entallador y ensamblador de nogal vecinos desta dicha villa y ambos veedores y examinadores de los dichos artes y gremios unidos de esta corte cuyos empleos se hallan actualmente ejerciendo en fuerza y virtud de nombramientos en ellos hecho, en junta celebrada por los individuos de dichos dos gremios en el dia 10 de agosto del año pasado de 1749; paso ante mi el infrascripto escribano del numero como secretario de ambos Gremios de cuya certidumbre doy fee; mediante lo cual y como tales veedores y examinadores otorgan que dan todo su poder cumplido el que de ello se requiera y es necesario a Antonio Sanchez Buitrago y Gabriel Pedrero procuradores de los reales Consejos y a esteban de Escolar y Antonio Rama Palomino, que lo son del numero de esta villa y a cada uno insolidum general para que en nombre de los otorgantes como tales veedores y examinadores les defiendan y a dichos sus gremios en todos y qualesquieres pleitos y demandas civiles y criminales que a el presente tengan y adelante tuviesen movidos y que se removiesen; como si tales veedores y examinadores por qualesquier personas asi demandantes como demandados, para cuyas defensas parezca ante V.M. señores de sus reales Consejos y demas audiencias y tribunales [...] y hagan alegaciones, pedimentos, requerimientos protestas, pidan ejecuciones, provisiones, escritura, embargos [...] y suscriban las ordenanzas que tienen para su regimen dichos gremios y otro cualquier instrumento y justificacion, tachen y contradigan quanto en contrario se presentase, dijeren alegaciones, concluyan, pidan y oigan autos, sentencias interlocutorias y definitivas [...] apelen y supliquen [...] y lo hagan publicar y notificar a las personas y partes contra quienes fueren dirigidos [...] y finalmente hagan y ejecuten todas las diligencias que judicial y extrajudicialmente se requieran y sean necesarias hasta que los dichos pleitos se concluyan [...] asi lo diheron y otorgaron ante mi el dicho escribano a quienes doy fee conozco siendo testigos Baltasar Diaz, Joseph Naranjo y Bartolome de Santa Olalla, residentes en esta Corte.

Francisco Gomez Matias Suarez ante mi Thomas Franco Izquierdo

DOCUMENTO N. ${ }^{\circ} 11$.

A.H.P. Madrid. Protocolo 18.705.

Poder especial. Los gremios de ebanistas y ensambladores de nogal a favor de Joseph Lopez y Pedro Rodríguez.

1774, 30 de mayo.

Estando en la sala de Juntas del Convento y Colegio de Santo Tomas del orden de predicadores desta villa de Madrid, a treinta dias del mes de mayo de mil setecientos setenta y cuatro; habiendose juntado en dicha sala los dos gremios unidos de Ebanistas y ensambladores de nogal desta Corte, con citacion que hubo ante diem, como lo tienen al uso y costumbre para tratar y conferir las cosas pertenecientes a los referidos gremios bien y utilidad dellos y sus individuos: los señores Joseph Lopez y Pedro Dominguez, actuales veedores, Esteban de Vivar, apoderado de dichos gremios; Manuel Martin, Francisco Menendez, Francisco Berdugo, Andres Taroto, Ambrosio Zermeño, Antonio tejero, Miguel Gonzalez, Carlos García, Lazaro de Humar, Manuel Crespo, Fernando Martin, Vicente Mingo, Manuel Garcia, Bernardino Canals, Pedro de Flores, Simon Tordesillas, Josep Garcia, Francisco Martin, Manuel Rodriguez Blanco; 
Antonio Santos Rodriguez, Gregorio Lopez, Francisco Beltran, Juan Alvarez, Gaspar Rodriguez, Valentin Diaz, Antonio Adan, Manuel Sacristan y Alfonso Serrano; todos maestros de los dichos dos Gremios de Evanistas y ensambladores, confesando, como confiesan ser la mayor parte de los individuos de los que al presente se compone y en nombre de todos los demas ausentes, enfermos e impedidos que al presente son y en adelante fueren, por quienes prestaron voz y caupcion de rato grato, mannte pacto judicando solvendo de que estaran y pasaran por lo que aquí se contendra, vajo expresa obligación que hicieron de sus personas y vienes, y assi juntos y congregados dijeron que daban y dieron todo su poder cumplido el de por derecho se requiere y es necesario mas puede y debe valer a los dichos Joseph Lopez y Pedro Rodriguez veedores; a estevan de Vivar y Alonso Santos Muñoz, apoderados de dichos gremios y cada uno insolidum especialmente para que acudan al real y supremo Consejo de castilla o a la Junta de Comercio y pidan la aprobacion de las Ordenanzas que ha formado nuevamente esta comunidad y gremios, citandose solo la antigüedad de ellas a fin y efecto de que se puedan observar por los individuos, como tambien contra quienes se dirijen y que sea maior beneficio del publico estando por este medio varios perjuicios que se les ocasionen; para lo cual presentaran Pedimentos, Memoriales y demas documentos Testigos y probanzas, con las acusaciones convenientes oyendo autos y sentencias, interlocutores y definitivas consintiendo lo faborable y apelando lo perjudicial; ganando provisiones y demas despachos, los que presenten y hagan intimar con ellos donde y a quien se dirigieren; que para todo ello, cada cosa o parte, lo incidente y dependiente, les dan y otorgan este poder especial tan cumplido y amplio de suerte que por falta del o clausula que no incluia no dejen de hacer todo cuanto se ofrezca y lo mismo que esta comunidad haria presentes siendo con franca libre y general Administracion, facultad de injuiciar, jurar y que lo puedan sustituir, rebocar los nombrados y elegir otros de nuevo con relevacion en forma y assi mismo para que en defensa de dichos gremios puedan seguir todos los pleitos y denuncias que se ofreciesen, practicando todas las diligencias judiciales y extrajudiciales que sean necesarias y a la validacion de lo que se obrase y ejecutase con este instrumento obligan sus bienes y personas en forma, dieron poder a las justicias y jueces de S.M. para que a ello les compelan y apremien por todo rigor de derecho como si fuese por sentencia basadas en autoridad de cosas juzgada renunciaron las leyes, fueros y derechos de su fabor con la general en forma y la de todo menor hedad; en cuio testimonio assi lo otorgaron siendo testigo D.Domingo Antonio de Monteagudo, don Vicente Lopez de Victoria y Joseph Manzaneque, residentes en esta corte; y de los otorgantes a quienes doy fee conozco lo firmaron los que supieron y por lo que no, un testigo a su ruego $=$ Pedro Rodriguez

Estevan de Vivar

Carlos Garcia

Manuel Sacristan

Franco Hernandez

Francisco Beltran

Alfonso Serrano

Pedro de Flores

Antonio Adan

Lazaro de Humar

Juan Alvarez

\author{
Joseph Lopez \\ Bernardino Canales \\ Gaspar Rodriguez \\ Ambrosio Cermeño (autografas) \\ Bicente Mingo \\ Miguel Gonzalez \\ Andres Taroroto \\ Gregorio Lopez \\ Simon Tordesillas \\ Franco Berdugo
}


Manuel Garcia

Antonio Rodriguez

Balentin Diaz
Manuel Rodriguez Blanco

Josephe Garcia

Testigo y a ruego: Domingo Antonio

\section{BIBLIOGRAFÍA CITADA}

Aguiló Alonso, M. P. 1993. El Mueble en España. Siglos XV y XVII. Madrid: CSIC y Ed. Antiquaria.

AGUlLó Y COBO, M. 1978. Documentos sobre escultores, entalladores y ensambladores de los siglos XVI al XVIII. Valladolid: Universidad de Valladolid.

BARRIO MOYA, J. L. 1988. "La biblioteca y las colecciones artísticas...". PITTM 59: 621.

- 1989 “El castillo de Escalona según un inventario de 1747". Anales Toledanos XXVI: 325-349.

- 1990a. "Algunas noticias sobre D.Blas de Beaumont cirujano francés en el Madrid de Felipe V.. Anales del Instituto de Estudios Madrileños 28: 453.

- 1990b. "La librería y otros bienes del hidalgo gallego don Francisco Fdez.de Samieles en la Real Junta de Comercio, Moneda y Minas (1763)". El Museo de Pontevedra XIIV: 695.

- 1991. "La librería y otros bienes de doña Ana María de Soroa, dama guipuzcoana del siglo XVII. Real Sociedad Bascongada de Amigos del Pais XIVII, 1-2: 163-180.

- 1992. "El abogado guipuzcoano don Manuel de Ipenza, secretario de Fernando VI y Justicia del Tribunal de la Nunciatura". Anuario jurídico y económico escurialense XXIV: 636-646.

- 1995. "La librería de don Jose Ximenez, médico salmantino...”. Salamanca. Revista de Estudios 35-36: 339-52

- 1998a. "El inventario de bienes de don Nicolás Ventura Echevarría (1728)". Boletín de la Real Sociedad Bascongada de Amigos del País LIV, 2: 409.

- 1998b. "La biblioteca de doña Luisa de Urrieta, dama donostiarra en el Madrid de Felipe V", Ibid. LIV, 2: 435.

- 1999. "Los libros jurídicos de don Pedro Rosales y Medrano". Anuario Jurídico y Económico Escurialense XXXII: 1147 y ss.

GonZÁlez Palencia, A. 1953. Colección de Documentos sobre Madrid. Madrid: Instituto de Estudios Madrileños.

ENTRAMBASAGUAS, J. 1941. "Noticias de algunos entalladores, doradores y ensambladores que trabajaron en Madrid desde el final del siglo XVI hasta mediados del siglo XVII. Revista Nacional de Educación I. 8: 250.

LARRUGA, E. 1788. Memorias políticas y económicas sobre los frutos, comercio, fábricas $y$ minas de España. Madrid: Imp. Antonio Espina, t. II.

LÓPEZ CASTÁN, A. 1986. "Los gremios artístico-industriales madrileños en el siglo XviII". Villa de Madrid 87: 17-30.

- 1989. "Los gremios de la madera en el Madrid de Carlos III y la Real Sociedad Económica Matritense de Amigos del Paísn. Boletín del Instituto de Estudios Madrileños XXVII: 345-379.

- 1991. "El gremio de ebanistas entalladores y ensambladores de nogal de Madrid en el siglo XVI, notas para su historia", en Veläzquez y el arte de su tiempo: 349356. Madrid: CSIC. 
- 1998. "El Gremio de Ebanistas de Madrid en el siglo XVIII". Boletín del Museo e Instituto Camón Aznar 71: 201-215.

MOLAS, P. 1972. Los gremios de Barcelona en el siglo XVIII. Barcelona: Universidad de Barcelona.

PIERA MIQUel, M. 1997. Los mueblistas de Barcelona a finales del siglo XVIII. Barcelona: Universidad de Barcelona. Memoria de Licenciatura.

- 1998. "El Album del marqués de la Victoria y su aportación a la historia del mueble». Archivo Español de Arte 281: 78-83.

- 2000. "El cadirers de boga a la Barcelona de la fi del segle XVIII". Afers. Fulla de recerca $i$ pensament 37: 633-640.

PIERA Miquel, M. y A. Mestres. 1999. El Moble a Catalunya. L'espai domèstic del Gòtic al Modernisme. Barcelona: Fundació CaixaManresa-Angle Editorial.

SymONDS, R. W. 1935. "Giles Grendey and the export trade of english furniture to Spain". Apollo XXII: 337-342.

- 1941. "English eighteenth century furniture to Spain and Portugal". The Burlington Magazine LXXVIII: 57-60. 